\title{
Self-Cleaning Coatings Activated by Solar and Visible Radiation
}

\section{Corrado Garlisi, Gabriele Scandura, Adetunji Alabi, Oluwadamilola Aderemi and Giovanni Palmisano*}

Department of Chemical and Environmental Engineering, Institute Center for Water and Environment (iWater), Masdar Institute of Science and Technology, Abu Dhabi $U A E$

\section{Introduction}

Self-cleaning behavior refers to the ability of a solid surface to remove contaminants under natural circumstances. This may be reached by two approaches. The former one is to achieve hydrophilic surfaces (water contact angle $\mathrm{WCA}<90^{\circ}$ ) on which water forms sheets, washing away impurities; the latter is to realize hydrophobic structures (WCA $>90^{\circ}$ ), causing droplets to form and roll over the surface quickly. Many research efforts have been made to find the extreme limits of wetting and non-wetting behavior by the development of a wide variety of engineered surfaces with superhydrophilic (WCA approaching zero) and superhydrophobic $\left(\mathrm{WCA}>150^{\circ}\right)$ properties.

Hydrophophilic/superhydrophilic coatings are generally made up of metal oxides. These materials are all semiconductors activated by light of certain wavelengths. Titania-based films are by far the most investigated hydrophilic materials because of their abilities to reach the superhydrophilic state and chemically break down organic dirt when exposed to sunlight, thanks to their photocatalytic reactivity. In addition $\mathrm{TiO}_{2}$ is stable, atoxic, and cheap.

The generation of holes and electrons occurs when light with energy equal to or greater than band gap is absorbed. Although the majority of the charges self-recombine, few of them reach the surface and give rise to redox reactions. Thus, holes can oxide the organic molecules whereas electrons react with atmospheric oxygen to generate superoxide radicals and further reactive oxygen species, which degrade pollutants on $\mathrm{TiO}_{2}$ surface [1], as shown in Figure 1a.

As illustrated in Figures 1b-1d, the photoinduced hydrophilic mechanism implies that holes diffusing to the surface are trapped at oxygen lattice atoms, weakening the bond between titanium and oxygen which is then interrupted by a water molecule. This results in -OH surface groups with high affinity for water, so that water molecules can form a uniform sheet on the surface rather than single drops. In the dark, hydroxyl groups progressively desorb from the surface in the forms of $\mathrm{H}_{2} \mathrm{O}_{2}$ or $\mathrm{H}_{2} \mathrm{O}$ and $\mathrm{O}_{2}$ molecules [2-4].

Applications are extensive and, among photocatalytic glasses already in the market, we find Pilkington Activ and PPG Sun Clean', which achieve self-cleaning behavior of glass for the construction industry.

The wide band gap $(3 \div 3.2 \mathrm{eV})$ of $\mathrm{TiO}_{2}$, however, does not allow for an efficient absorption of visible radiation, which is the most abundant part of the solar light and the only natural radiation existing indoors. Another important drawback of $\mathrm{TiO}_{2}$ is the drop of hydrophilicity in a dark state.

The following are some of the many attempts made so far to overcome $\mathrm{TiO}_{2}$ limitations.

\section{Nitrogen-doped $\mathrm{TiO}_{2}$}

Due to its comparable atomic size with oxygen, high stability and low ionization energy, nitrogen $(\mathrm{N})$ can be easily introduced into crystal lattice either by interstitial or substitutional incorporation to enhance visible light-induced photocatalysis [5]. Theoretical studies modelling the density of state within the conduction band of doped $\mathrm{TiO}_{2}$, show how the substitutional doping of $\mathrm{N}$ is the most effective because its $2 \mathrm{p}$ states contribute to the band-gap narrowing by mixing with $\mathrm{O} 2 \mathrm{p}$ states, thereby improving visible light absorption [6].

The incorporation of nitrogen induces the formation of oxygen vacancies, which increase the visible light activity by acting as color centers in generating new absorption sites, or by acting as electron traps. The latter event occurs as an electron is promoted to the oxygen vacancy state from the valence band. These electrons react with atmospheric oxygen, whereas holes can interact with water or superoxide radicals, eventually giving rise to reactive oxygen species, which, on their turn, trigger the oxidation reactions.

The most versatile technique to obtain $\mathrm{N}-\mathrm{TiO}_{2}$ is the sol-gel method in which $\mathrm{N}$-containing precursors, such as ammonium salts, nitrates, urea, etc., are easily added to the starting colloidal solution, allowing fine control of the material's nanostructure morphology and porosity. Eventually, this results in an enhanced photocatalityc activity and visible-light response [7]. Recently, many attempts have been made to further increase $\mathrm{N}$-doped titania performance, by adding additional doping elements to the colloidal solutions. Together with nitrogen, vanadium and fluorine have been found to shift the absorption edge to visible light and increase hydrophilicity $[8,9]$.

\section{$\mathrm{Cu}-\mathrm{TiO}_{2}$}

A different but equally key approach to improve the self-cleaning properties of titania is by the dispersion of metal nanoparticles in the $\mathrm{TiO}_{2}$ matrix.

An example of this method is the fabrication of $\mathrm{TiO}_{2}$ thin films on inert support with a gradient of $\mathrm{Cu}$ doping through layer-by-layer dipcoating [10]. Liu and co-workers reported how the band gap of $\mathrm{TiO}_{2}$ can be narrowed, as the loaded copper increases. This occurs since $\mathrm{Cu}$ atoms replace $\mathrm{Ti}$ ones in the $\mathrm{TiO}_{2}$ crystal lattice yielding the formation of $\mathrm{Ti}_{1-\mathrm{y}} \mathrm{Cu}_{\mathrm{y}} \mathrm{O}_{2}$ phase. So, the smaller gap between $\mathrm{Ti}$ and $\mathrm{O}$ atoms easily permits the transfer of photoexcited electrons from $\mathrm{O}_{2 \mathrm{p}}$ to $\mathrm{Ti}_{3 \mathrm{~d}}$ orbitals [11].

In other words, the thin film interacts with a wider spectrum of light (including visible light) thanks to its layers at different band gaps. The band gap gradient mainly prevents the recombination of photoexcited charge carriers leading a further beneficial aspect to the film structure.

*Corresponding author: Giovanni Palmisano, Department of Chemical and Environmental Engineering, Institute Center for Water and Environment (iWater), Masdar Institute of Science and Technology, PO BOX 54224, Abu Dhabi, UAE, Tel: +971 8109246; E-mail: gpalmisano@masdar.ac.ae

Received Februay 27, 2015; Accepted March 05, 2015; Published March 10 2015

Citation: Garlisi C, Scandura G, Alabi A, Aderemi O, Palmisano G (2015) SelfCleaning Coatings Activated by Solar and Visible Radiation. J Adv Chem Eng 5: e103. doi: 10.4172/2090-4568.1000e103

Copyright: ( 2015 Garlisi C, et al. This is an open-access article distributed under the terms of the Creative Commons Attribution License, which permits unrestricted use, distribution, and reproduction in any medium, provided the original author and source are credited. 


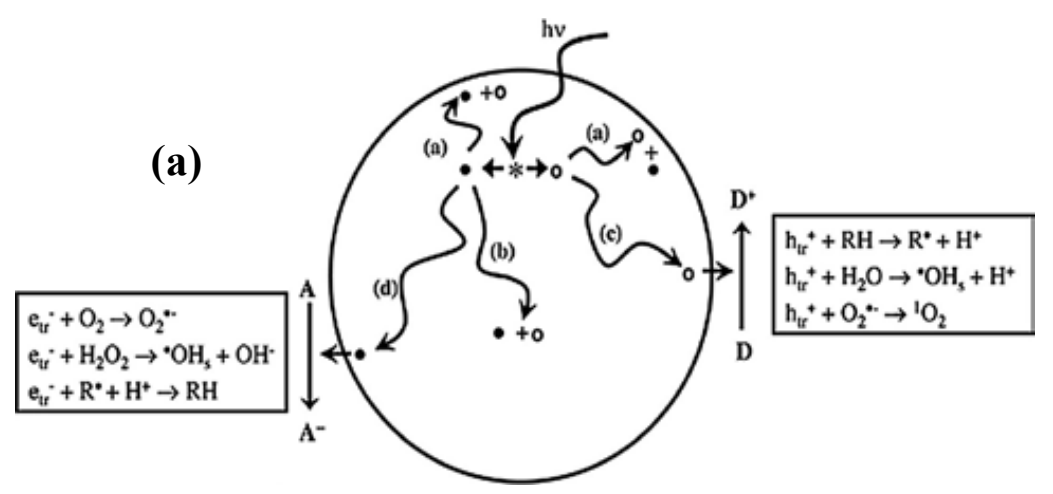

(b)

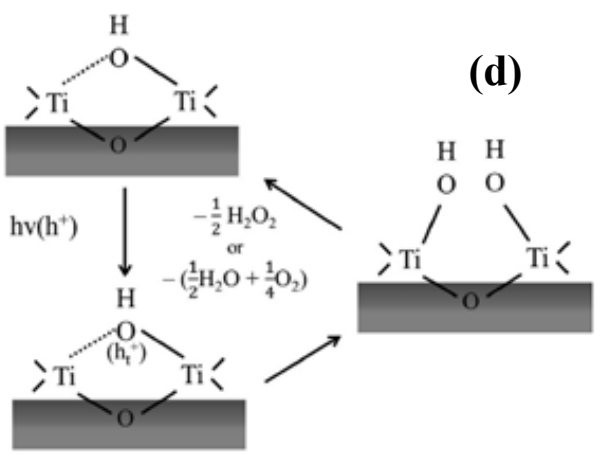

Figure 1: (a) The processes occurring on bare $\mathrm{TiO}_{2}$ particle after its excitation causing degradation of organic species [3]. (b-d) Surface structural models for the TiO surface; (b) before irradiation the $\mathrm{OH}$ group is bound to oxygen vacancy; (c) at the transition state the photogenerated hole is trapped at the lattice oxygen; and (d) after irradiation new $\mathrm{OH}$ groups are formed [4].

The Copper concentration gradient in the $\mathrm{TiO}_{2}$ thin film reduces the WCA by 1.3, 2.2, and 4.4 times before illumination, after visible light irradiation, and after UV-visible light irradiation respectively, compared with that in the pure $\mathrm{TiO}_{2}$ film.

\section{Silica/Titania composite films}

Titania-silica materials have been obtained with a great variety of morphologies: atomically mixed oxides, zeolites, nanoscopic titania in a silica matrix, (multi)layered thin films, etc. [12].

The presence of silica generally increases the hydrophilic properties of $\mathrm{TiO}_{2}$ films, giving them long-lasting superhydrophilic behavior even after many days in a dark state. The enhanced performance can be ascribed to the silicon cation, which remains connected to the same number of oxygen atoms despite the latter now having a new coordination; this produces a charge imbalance. Therefore, Lewis sites are expected to form because of the positive charge in a $\mathrm{TiO}_{2} /$ $\mathrm{SiO}_{2}$ binary metal oxide, thereby improving adsorption of water and photocatalytic reactivity [13].

Many authors have been reported significant photocatalytic activity and hydrophilicity of sol-gel mesoporous silica functionalized by $\mathrm{TiO}_{2}$. The mesoporous structure improves the self-cleaning properties compared to a microporous matrix embedded with $\mathrm{TiO}_{2}$ particles because of the increased BET surface area. This contributes to accelerate the diffusion of organic pollutants toward the titania particles [14], acting both as adsorption sites for water molecules and photocatalytic centers. Moreover, the mesoporous silica owns a great number of silanol groups on its inner surface and can favour capillary phenomena [15].

Another effective approach involves the synthesis of silica-titania nanocomposites with a core/shell structure. In particular, layerby-layer assembly provides a convenient and inexpensive way to produce coatings with tailored chemical composition and controllable architecture.

\section{Layer-by-layer $\mathrm{TiO}_{2}-\mathrm{WO}_{3}$ films}

Some authors reported $\mathrm{TiO}_{2}-\mathrm{WO}_{3}$ films exhibit a better electronhole separation efficiency in contrast to the bare $\mathrm{TiO}_{2}[16,17]$. Indeed, by diffuse reflectance measurements along with ultraviolet photoemission spectroscopy (UPS) allowed to understand that in the $\mathrm{TiO}_{2}-\mathrm{WO}_{3}$ films, produced by the layer by layer (LbL) technique, the valence band (VB) maximum remains almost untouched compared to pure LbL
$\mathrm{TiO}_{2}$ films, and the $\mathrm{WO}_{3}$ conduction band (CB) introduces new lowlying electronic levels in the relation to the $\mathrm{CB}$ of $\mathrm{TiO}_{2}$ [18]. Hence, under $\mathrm{UV}(\mathrm{A})$ irradiation the photogenerated electrons in the $\mathrm{TiO}_{2}$ are transferred to low-lying $\mathrm{WO}_{3} \mathrm{CB}$ and here they are trapped while the holes are free to move within the $\mathrm{VB}$ of both oxides. For this reason, the wettability of the heterostructure is improved: the so prepared films showed, after UV(A) irradiation, a WCA $<5^{\circ}$ for more than $96 \mathrm{~h}$ after storage in the dark at ambient conditions.

Moreover, the $\mathrm{LbL} \mathrm{TiO}_{2}-\mathrm{WO}_{3}$ films displayed a higher photocatalytic activity than pure $\mathrm{TiO}_{2}$ film. Notably, the $\mathrm{W}(\mathrm{VI}) / \mathrm{Ti}(\mathrm{IV})$ ratio must be low. Conversely, the photochromism phenomena happens: electrons overstock at the $\mathrm{WO}_{3} \mathrm{CB}$ and as a consequence the latter is too positive to reduce $\mathrm{O}_{2}$ to superoxide radicals $\left(\mathrm{O}_{2}^{--}\right)$, so the photocatalytic reaction rates drop significantly. In addition, the accumulated electrons could react with $\cdot \mathrm{OH}$ radicals to yield $\mathrm{OH}^{-}$anions $[19,20]$. Nevertheless, the $\mathrm{LbL} \mathrm{TiO}_{2}-\mathrm{WO}_{3}$ films did not exhibit significant visible-light photoactivity.

\section{Conclusion}

One of the greatest challenges in the photocatalysis field is to enhance the visible-light activity and long-lasting (in dark conditions) superhydrophilic behavior of titania. In spite of the commendable efforts by the scientific and industrial community, further improvements are needed for a broader scale utilization of titania based-films in commercial application.

\section{References}

1. Liu K, Cao M, Fujishima A, Jiang L (2014) Bio-inspired titanium dioxide materials with special wettability and their applications. Chem Rev 114: 10044-10094.

2. Yao L, He J (2014) Recent progress in antireflection and self-cleaning technology-From surface engineering to functional surfaces. Prog Mat Sci 61: 94-143.

3. Foran PS, Boxall C, Denison KR (2012) Photoinduced superhydrophilicity: a kinetic study of time dependent photoinduced contact angle changes on $\mathrm{TiO} 2$ surfaces. Langmuir 28: 17647-17655.

4. Sakai N, Fujishima A, Watanabe T, Hashimoto K (2003) Quantitative evaluation of the photoinduced hydrophilic conversion properties of $\mathrm{TiO} 2$ thin film surfaces by the reciprocal of contact angle. J Phys Chem B 107: 1028-1035.

5. Pelaez M, Nolan NT, Pillai SC, Seery MK, Falaras P, et al. (2012) A review on the visible light active titanium dioxide photocatalysts for environmental applications. Appl Catal B Environ 125: 331-349.

6. Asahi R, Morikawa T, Ohwaki T, Aoki K, Taga Y (2001) Visible-light photocatalysis in nitrogen-doped titanium oxides. Science 293: 269-271. 
Citation: Garlisi C, Scandura G, Alabi A, Aderemi O, Palmisano G (2015) Self-Cleaning Coatings Activated by Solar and Visible Radiation. J Adv Chem Eng 5: e103. doi: 10.4172/2090-4568.1000e103

Page 3 of 3

7. Zuo JS, Wei CP, Peng CJ, He RY, Wang GD (2014) Preparation and properties characterization of N-doped TiO2 film. Mater Sci Forum 809: 573-577.

8. Khatibnezhad H, Sani MAF (2014) Preparation and characterization of nanostructured $\mathrm{TiO} 2$ thin film codoped with nitrogen and vanadium on glass surface by sol-gel dip-coating method. Res Chem Intermed.

9. Kontos AG, Pelaez M, Likodimos V, Vaenas N, Dionysiou DD, et al. (2011) Visible light induced wetting of nanostructured $\mathrm{N}-\mathrm{F}$ co-doped titania films. Photochem Photobiol Sci 10: 350-354

10. Liu Z, Wang Y, Peng X, Li Y, Liu Z, et al. (2012) Photoinduced superhydrophilicity of TiO2 thin film with hierarchical Cu doping. Sci Technol Adv Mater 13: 025001.

11. Carvalho HW, Batista AP, Hammer P, Ramalho TC (2010) Photocatalytic degradation of methylene blue by $\mathrm{TiO} 2-\mathrm{Cu}$ thin films: theoretical and experimental study. J Hazard Mater 184: 273-280.

12. Seriani N, Pinilla C, Cereda S, De Vita A, Scandolo S (2012) Titania-silica interfaces. J Phys Chem C 116: 11062-11067.

13. Augugliaro V, Loddo V, Pagliaro M, Palmisano G, Palmisano L (2010) Clean by light irradiation: practical applications of supported TiO2, Cambridge, Royal Society of Chemistry.
14. Pinho L, Mosquera MJ (2011) Titania-silica nanocomposite photocatalysts with application in stone self-cleaning. J Phys Chem 115: 22851-22862.

15. Horiuchi Y, Yamashita H (2011) Design of mesoporous silica thin films containing single-site photocatalysts and their applications to superhydrophilic materials. Appl Catal A Gen 400: 1-8.

16. Djaoued Y, Balaji S, Beaudoin N (2013) Sol-Gel synthesis of mesoporous WO3TiO2 composite thin films for photochromic devices. J Sol-Gel Sci Technol 65: 374-383.

17. Park H, Bak A, Jeon TH, Kim S, Choi W (2012) Photo-Chargeable and Dischargeable TiO2 and WO3 heterojunction electrodes. Appl Catal B 115: 7480.

18. Patrocinio AO, Paula LF, Paniago RM, Freitag J, Bahnemann DW (2014) Layer-by-layer $\mathrm{TiO}(2) / \mathrm{WO}(3)$ thin films as efficient photocatalytic self-cleaning surfaces. ACS Appl Mater Interfaces 6: 16859-16866.

19. Riboni F, Bettini LG, Bahnemann DW, Selli E (2013) WO3-TiO2 vs TiO2 photocatalysts: effect of the $\mathrm{W}$ precursor and amount on the photocatalytic activity of mixed oxides. Catal Today 209: 28-34.

20. Yang J, Zhang X, Liu H, Wang C, Liu S, et al. (2013) Heterostructured TiO2 WO3 porous microspheres: preparation, characterization, and photocatalytic properties. Catal Today 201: 195-202. 